\title{
A preference in rats for cues associated with intoxication
}

\author{
ROGER W. BLACK, TONY ALBINIAK \\ MELVIN DAVIS, and JOSEPH SCHUMPERT \\ University of South Carolina, Columbia, S.C. 29208
}

Rats were placed in one compartment of a shuttlebox following ethanol injection and in another compartment following injection with saline. After four or five injection placements in each compartment, Ss showed a preference for the compartment associated with ethanol injection. Noninjected Ss given the series of placements did not develop such a preference. These results suggested that the central effects of ethanol (intoxication) are reinforcing for rats.

Approaches to alcoholism based on learning principles generally attribute the development of chronic excessive drinking to some reinforcing property of ethanol for the human alcoholic (e.g., Vogel-Sprott, 1972). Presumably, it should be possible to demonstrate these effects in an appropriate animal model. For example, reinforcing properties might be inferred if animals showed a preference for ethanol solutions relative to other fluids or if they voluntarily consumed ethanol in increasing intoxicating quantities. Most laboratory animals, however, appear to find ethanol solutions aversive and drink relatively little of them (Lester, 1966; Myers \& Veale, 1972). Thus, ethanol-consumption studies have provided little evidence of a reinforcing effect of ethanol for animals. These studies, of course, do not indicate whether the central effects of ethanol (i.e., intoxication) are reinforcing. Thus, the present study involved an attempt to determine if rats would develop a preference for a compartment in which they were intoxicated relative to a compartment in which they were not intoxicated. The development of such a preference would suggest that the central effects of ethanol are reinforcing for rats and would be consistent with interpretations of human alcoholism based on reinforcement principles.

\section{METHOD}

The 13 Ss were 100-day-old male Sprague-Dawley rats. The Ss were housed in individual cages with ad lib food and water available throughout the experiment. The apparatus was a modified Lafayette shuttlebox, which consisted of two compartments separated by a sliding metal door. One compartment, constructed of wood and painted black, was $12.7 \mathrm{~cm}$ wide, $21.6 \mathrm{~cm}$ long, and $12.7 \mathrm{~cm}$ high. The other compartment, constructed of sheet metal and painted light gray, was $20.3 \mathrm{~cm}$ wide, $30.5 \mathrm{~cm}$ long, and $30.5 \mathrm{~cm}$ high. The floor of both compartments was a grid of steel bars, and both were covered with clear Plexiglas.

The first experiment was conducted in three phases: a single pretest day, 8 confinements days, and 4 preference-test days. A 48-h interval of rest in the home cage was provided after each experimental day throughout the experiment. On the pretest day, each $\mathrm{S}$ was placed individually in the apparatus at the open door between compartments and allowed to explore for $30 \mathrm{~min}$. The time $S$ spent in each compartment was automatically recorded. The compartment in which each $\mathrm{S}$ spent more time on this day was designated arbitrarily as Compartment $\mathrm{A}$ and the other compartment as Compartment $B$ for that $S$ for the remainder of the experiment. During the confinement and preference test phases, five Ss served as the injected group and three Ss served as the noninjected group. On each of the 8 confinement days, each noninjected $S$ was placed in one of the compartments, with the door between compartments closed, and was confined there for $15 \mathrm{~min}$, after which it was returned to its home cage. On Confinement Days 1, 3, 5, and 7, Ss were placed in Compartment $B$, while on Days $2,4,6$, and 8 , they were placed in Compartment $A$. The injected Ss were treated identically, except that $5 \mathrm{~min}$ before they were placed in the apparatus they were injected intraperitoneally with either $10 \%$ ethanol solution (equivalent to $1 \mathrm{~g}$ of absolute ethanol per kilogram bodyweight) or with a saline placebo of equal volume. The ethanol injection was given before each placement in Compartment $\mathrm{B}$, while saline was injected before placing $\mathrm{S}$ in Compartment $A$. The procedure on the 4 preference-test days was identical to that on the pretest for the noninjected Ss. The procedure for the injected Ss was also identical to the pretest, except that on Test Days 1 and 3 they received the ethanol injection, while on Test Days 2 and 4 they received the saline injection. Since a 48 -h rest interval was provided between each experimental day, the first experiment was conducted over 25 consecutive days.

The second experiment was identical to the first, except that (1) only one group of five injected Ss was employed; (2) the number of confinement days was increased from 8 to 10 , providing five confinements in each compartment; and (3) the order in which ethanol and saline injections were administered was reversed. Thus, ethanol was injected on Confinement Days $2,4,6,8$, and 10 , on which $S$ was injected with saline and placed in Compartment A. Ethanol was injected on Test Days 2 and 4 and saline on Test Days 1 and 3.

\section{RESULTS}

During the confinement phase, the injected Ss showed gross motor incoordination and other signs of intoxication almost immediately following the ethanol injection. These disturbances in behavior persisted through the confinement period, but were less apparent by the time $\mathrm{S}$ was returned to its home cage. The Ss did not appear to sleep or to become unconscious during the confinement period following ethanol injection. The Ss showed little effect of the saline injection procedure except for an appearance of general fearfulness (cowering, etc.) in Compartment A.

The data for the first experiment were the proportions of time spent by each $\mathrm{S}$ in Compartment B on the pretest day and each preference-test day. For the injected group, the differences between these 5 days were significant $(F=4.23, \mathrm{df}=4 / 16, \mathrm{p}<.02)$. There was no significant difference between Test Days 1 and 3 (ethanol-injection) $(\mathrm{t}=0.93, \mathrm{df}=4)$ or between Test Days 2 and 4 (saline-injection) $(\mathrm{t}=.29 \mathrm{df}=4)$. The mean proportions for these combined days, the pretest and the comparable days for the noninjected Ss, are presented in Table 1. On saline-injection days. the injected Ss showed a significant increase in time spent in Compartment $B$ relative to pretest $(t=11.78 . \mathrm{df}=4$. $p<.001)$. They also showed a significant preference for 
Table 1

Mean Proportion of Time in Compartment B

\begin{tabular}{lccc} 
& & \multicolumn{2}{c}{ Test Days } \\
\cline { 3 - 4 } Group & Pretest & 1 and 3* & 2 and 4** \\
\hline $\begin{array}{l}\text { Noninjected } \\
\text { (Experiment I) }\end{array}$ & .30 & .36 & .39 \\
$\begin{array}{l}\text { Injected } \\
\text { (Experiment I) }\end{array}$ & .22 & .46 & .74 \\
$\begin{array}{l}\text { Injected } \\
\text { (Experiment II) }\end{array}$ & .18 & .89 & .80 \\
\hline
\end{tabular}

*Ethanol-injection days of Experiment I

${ }^{* *}$ Ethanol-injection day's of Experiment II

Compartment B relative to Compartment $\mathrm{A}(\mathrm{t}=3.10, \mathrm{df}$ $=4 . p<.05)$. On ethanol-injection days, however, these $\mathrm{Ss}$ failed to show a preference between the compartments $(t=.32, \mathrm{df}=4)$, and the increase relative to pretest only approached significance $(\mathrm{t}=2.29, \mathrm{df}=4$, $.1>\mathrm{p}>.05)$. The noninjected Ss neither came to prefer Compartment $B$ nor to show a significant increase in time in it relative to pretest $(\mathrm{t}=.66, \mathrm{df}=2)$.

The group of injected Ss of the second experiment (Table 1) showed a significant preference for Compartment $B$ on both saline-injection $(t=6.76, \mathrm{df}=$ $4, \mathrm{p}<.01)$ and ethanol-injection test days $(\mathrm{t}=4.00, \mathrm{df}=$ 4. $p<.05)$, and the proportion of time in Compartment B did not differ significantly between these test days $(t=1.48, d f=4)$. Nevertheless, four of these five Ss did spend more time in Compartment B on saline on ethanol-injection days, as did all five injected Ss in the first experiment. When the injected groups from the two experiments were viewed as comprising a single, two-factor design with ethanol vs saline-injection test days as one (repeated-measures) factor and 8 vs 10 confinement days ("experiments") as the other factor, the main effects of both factors were significant. Thus,
Ss spent more time in Compartment B on saline-injection than on ethanol-injection days $(F=9.69$. $\mathrm{df}=1 / 8, \mathrm{p}<.02)$ and $\mathrm{Ss}$ which received 10 confinement periods in the apparatus showed a stronger preference for Compartment $B$ than Ss which received only eight confinements $(F=5.92, \mathrm{df}=1 / 8, \mathrm{p}<.05)$.

\section{DISCUSSION}

The present results indicate that the procedure of associating intoxication with Compartment $B$ led to a preference for that compartment relative to Compartment $A$, in spite of the Ss' initial preference for the latter. In this sense, the central effects of ethanol were reinforcing. One interpretation of this result might be that the rats "liked" being intoxicated or found it rewarding in some positive sense. Observation of the injected Ss suggested, however, that the situation was more aversive than appetitive. Thus, the procedure of handling and injecting the Ss before placing them in the apparatus appeared to produce strong emotional responses which were likely to become associated with the compartment in which the Ss were subsequently confined. These emotional responses presumably were attenuated by the ethanol injection and were thus less strongly associated with Compartment B. The preference for Compartment $B$ during the subsequent tests, therefore, may have reflected the relative aversiveness of the two compartments. The tendency for the preference for Compartment B to be weaker on ethanol-injection test days than on saline-injection days is also consistent with the view that ethanol reduced the strength of aversive tendencies (cf. Conger, 1951).

\section{REFERENCES}

Conger, J. J. The effects of alcohol on conflict behavior in the albino rat. Quarterly Journal of Studies on Alcohol, 1951, 12 , 1-29.

Lester, D. Self-selection of alcohol by animals, human variation, and the etiology of alcoholism. Quarterly Journal of Studies on Alcohol, 1966, 27, 395-438

Myers, R. D. \& Veale, W. L. The determinants of alcohol preference in animals. In B. Kissin and H. Begleiter (Eds.), The biology of alcoholism. New York: Plenum Press, 1972.

Vogel-Sprott, M. Alcoholism and learning. In B. Kissin and $\mathrm{H}$ Begleiter (Eds.), The biology of alcoholism. New York: Plenum Press, 1972.

(Received for publication September 4, 1973.) 